\title{
Mudanças nos Padrões de Consumo de Alimentos das Classes Econômicas na Região Norte
}

\author{
Alexandre G. Maia, Gisele Elaine de A. B. Souza, Theodora* P. Beluzzi
}

\begin{abstract}
Resumo
Como contribuição ao estudo dos efeitos da agricultura de grande escala na população rural da Região Norte, este trabalho analisa as mudanças no consumo alimentar dessas famílias, comparando microdados fornecidos pela Pesquisa de Orçamento Familiar (POF - feita pelo IBGE) dos anos de 2002/2003 e 2008/2009, categorizados por fatores sociais e demográficos.
\end{abstract}

\section{Palavras-chave \\ Pesquisa de Orçamento Familiar, Consumo alimentar, Região Norte.}

\section{Introdução}

Diante do processo histórico de favorecimento à grande propriedade rural brasileira e do notável crescimento da agricultura de grande escala, sobretudo na região Norte do país, colocando gradativamente à margem a grande maioria das famílias rurais, surge a questão central dos efeitos que essa marginalização provoca. Este trabalho procurou estudar as mudanças nos padrões de aquisição e consumo de alimentos da população rural dos estados do Norte, de modo a explorar os efeitos das transformações econômicas dos últimos anos daquela região. Para isso, foram utilizados os dados de duas edições da Pesquisa de Orçamento Familiar (POF) 2002/2003 e 2008/2009.

\section{Resultados e Discussão}

A POF é uma pesquisa feita pelo IBGE que tem como principal objetivo mensurar as estruturas de consumo, dos gastos, rendimentos e parte da variação patrimonial das famílias. Consegue assim, definir os hábitos e condições de vida da população brasileira.

Para os dados nutricionais foi utilizada a tabela de macro nutrientes fornecidos pela POF 2008/2009. Como proxy do consumo alimentar, foi utilizada a aquisição de alimentos, contemplada pelo terceiro questionário da POF. Foi feito também um esforço de categorização dos alimentos: todos os itens alimentares foram classificados, um a um, em 21 categorias: Açúcares e derivados; Alimentos preparados; Aves e ovos; Bebidas Alcoólicas; Bebidas não alcoólicas e Infusões; Bolos e biscoitos; Carnes e Vísceras; Carnes industrializadas; Cereais, leguminosas e oleaginosas; Condimentos Naturais e Processados; Enlatados e conservas; Farinha, féculas e massas; Frutas; Legumes, verduras e hortaliças; Leite e derivados; Miscelâneas; Nozes, sementes e castanhas; Óleos e Gorduras; Panificados; Pescados e frutos do mar; Pizzas e Salgados; Tubérculos e raízes. Para a determinação dessas classificações, apoiou-se em trabalhos prévios, como o de KAWAMURA (2014), e na classificação da própria POF de 2008. Além disso, foram estabelecidas variáveis categóricas para anos de estudo, faixas de renda, faixa etária, sexo, cor, escolaridade, forma de aquisição do produto.

O consumo de alimentos caiu de um modo geral, na comparação da edição de 2008/2009 com a de 2002/2003, sem considerar nenhuma classificação demográfica ou socioeconômica: a queda na aquisição de alimentos provocou queda de calorias adquiridas em $15,47 \%$; proteínas caíram 9,35\%; carboidratos caíram 23,57\%; Fibras caíram $28,45 \%$; apenas os lipídios tiveram um ligeiro aumento de $1,51 \%$.

Levando em consideração as classes de renda, o estrato superior com renda per capita maior que $\mathrm{R} \$$ 900,00 mensais foi o único que teve aumento em todas as categorias de macro nutrientes. O segundo estrato renda per capita entre $R \$ 450,00$ e $R \$ 900,00$ verificou um aumento em fibras e carboidratos $(23,05 \%$ e $2,50 \%$ respectivamente) e queda nos outros macros nutrientes. Os outros estratos com rendas per capita menores, só verificaram quedas.

Olhando para as formas de obtenção, a participação da forma de produção monetária cresce em detrimento da produção própria e das outras classificações (doação, troca, retirada do negócio, outros): é a categoria que cresce em participação de forma de obtenção em todos os estratos de renda.

\section{Conclusões}

A aquisição de alimentos das famílias rurais do Norte do país caiu no período analisado. Além disso, as formas de obtenção também mudam: as formas monetárias crescem em detrimento da produção própria e de outras formas, como retirada do negócio, doação e troca. Os resultados sugerem sim, mudanças no padrão de consumo alimentar das famílias, e abre novas perspectivas para a pesquisa, como a qualificação dessa mudança, as implicações socioeconômicas dela e fatores de contribuição para esse processo.

\section{Agradecimentos}

Agradeço ao Programa Institucional de Bolsas de Iniciação Científica e Tecnológica da UNICAMP, pelo financiamento do projeto.

KAWAMURA, H.C., Efeitos do Programa Bolsa Família no consumo de nutrientes e índices Antropométricos, 2014, 104 f. Tese (Doutorado em Ciências Econômicas - Escola Superior de Agricultura "Luiz de Queiroz", Universidade de São Paulo, Piracicaba, 2014. 